\title{
AÇÃO REVOCATÓRIA: A DIMENSÃO DA DICOTOMIA "INEFICÁCIA OBJETIVA" E "INEFICÁCIA SUBJETIVA" (ARTIGOS 129 E 130 DA LEI 11.101/05)
}

TESE DE DOUTORADO

ORIENTADOR: PROFESSOR DOUTOR ORESTE NESTOR DE SOUZA LASPRO

FACULDADE DE DIREITO DA UNIVERSIDADE DE SÃO PAULO São Paulo 2012 
CLARA MOREIRA AZZONI

\title{
AÇÃO REVOCATÓRIA: A DIMENSÃO DA DICOTOMIA "INEFICÁCIA OBJETIVA" E "INEFICÁCIA SUBJETIVA" (ARTIGOS 129 E 130 DA LEI 11.101/05)
}

\begin{abstract}
Tese para doutorado apresentada à Banca Examinadora da Faculdade de Direito da Universidade de São Paulo, como exigência para obtenção do título de Doutor em Direito Processual, sob orientação do Professor Doutor Oreste Nestor de Souza Laspro.
\end{abstract}

Faculdade de Direito da Universidade de São Paulo São Paulo 
Aos meus pais, a quem atribuo o mérito por todas as minhas conquistas.

Ao Marcos, pelo amor, incentivo e paciência. 